\title{
A Novel Oblique Impact Test Rig for Testing Helmet
}

\author{
Daniel E Abram*, Adrian Wikarna, Farid Golnaraghi and G Gary Wang
}

Head Injury Prevention Laboratory, Simon Fraser University, Canada

*Corresponding author: Daniel Abram, Head Injury Prevention Laboratory, Simon Fraser University, Surrey, BC, V3T 0A3, Canada

\begin{abstract}
In this work, a new test rig is introduced to assess various head impact scenarios on different types of helmets. The test rig is a free-fall system where a helmeted headform is suspended instead of being placed on a basket frame and detaches from the system before the impact allowing an unrestricted motion. The proposed testbed showed to be effective in performing helmet impact tests at different angles. The test rig is particularly effective in tests at steep anvil angles, such as $15^{\circ}$, which could be problematic utilizing conventional test rigs with a basket frame. This is because, right before impacting the anvil, the helmeted headform is detached from the system enabling the helmeted headform to move freely during impact. In addition, the test results showed low CVs and high repeatability within the same impact scenario. The results showed that the proposed test rig could perform oblique impact tests on a wide range of angles without causing damage to the test rig. The results of the impact tests also suggest both the magnitude and duration of an impact are necessary for a more effective assessment of helmet performance.
\end{abstract}

\section{Keywords}

Biomechanics, Impact testing, Helmet, Oblique impact, Helmet assessment, Head injury

\section{Introduction}

Studies on the epidemiology of head injuries over the years have led to many advancements in the field of head protection. Helmets are mostly being designed and certified to minimize the risk of skull fractures, which have limited benefits for protecting against Traumatic Brain Injuries (TBI) and mild TBI [1-4]. Although current helmet certifications are mainly based on measuring the linear acceleration, many research studies have also linked TBI to the magnitude of rotation induced on the head due to significant shear strains exerted on brain tissues [5-8]. Rotational forces can increase the risk of TBI such as Diffuse Axonal
Injuries (DAI), Subdural Hematomas (SDH), and concussions [9-12]. According to statistics, the number of reported concussion incidence has increased [2] and it is believed to be attributed to factors such as more awareness of head injuries, higher population, and living a more active lifestyle $[13,14]$. To better predict the risk of head injury, helmets should be evaluated for their ability to mitigate both linear and rotational accelerations of the head.

Whyte, et al. [15] provided a thorough review of the methodologies and conditions for impact testing of helmets. One of the most common methods of testing involves Anthropomorphic Test Dummy (ATD) headforms, striking a stationary impact opponent via a guided vertical drop. Drop testing equipment in some studies follows the direction of various helmet testing standards that suggest guided wires and monorail systems [16-21]. In those studies, helmeted headform is fixedly attached to the moving carriages, which only allows the head to move along a single axis. While this may be adequate for measuring linear acceleration, the rigid connection prevents the rotational motion of the headform.

As other researchers considered the effects of the human neck and torso within the context of impact testing, the use of neckforms was introduced into testing methodologies [3,22-25]. Instead of developing a suitable neckform for helmet testing, a Hybrid III neck that was already available for vehicle crash testing was broadly used in helmet impact testing. However, Hybrid III necks are too stiff and known to have characteristics unlike that of a human neck [26-30]. As a result, some helmet impact evaluation methods adopted custom neck surrogates to substi-

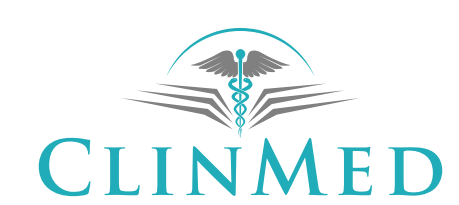

INTERNATIONAL LIBRARY
Citation: Abram DE, Wikarna A, Golnaraghi F, Wang GG (2020) A Novel Oblique Impact Test Rig for Testing Helmet. Int J Sports Exerc Med 6:158. doi.org/10.23937/2469-5718/1510158

Accepted: February 11, 2020; Published: February 13, 2020

Copyright: (C) 2020 Abram DE, et al. This is an open-access article distributed under the terms of the Creative Commons Attribution License, which permits unrestricted use, distribution, and reproduction in any medium, provided the original author and source are credited. 
tute the Hybrid III necks [26,31,32].

Aldman, et al. (1976) pioneered early studies of helmeted headform testing with a drop tower, which released an ATD head-neck assembly to fall freely onto a rotating disk platform. A horizontal velocity component is generated by the disk, which was prepared with various surface conditions, to emulate realistic accident scenarios wherein a helmet wearer strikes the ground head-first. Harrison, et al. (1996) had a similar approach to drop testing but with a deformable horizontally translating impact surface. This concept was further developed by Halldin, et al. (2001), wherein a detached helmeted headform was raised to a certain height via a monorail, and then dropped onto a gas-propelled steel plate [33]. An update to that design was applied where a Hybrid III headform was used, and an additional vertical rail reinforced the drop assembly [34]. Versions of the guided rail and moving horizontal surface format were later adopted using moving carriages with headneck assemblies [22,35].

Before the development of Halldin's oblique impact testing method, studies on the impact literature review, reconstruction, and analysis of motorcycle accidents were conducted as part of the European research action [36]. The impact tests presented in the final report described a drop test rig that utilized a support ring surrounded with several adjustable thin rods which hold the helmeted headform at a desired orientation [37]. Subsequent methods using basket supports, and adjustable rods were fashioned for free fall impact tests on bicycle helmets [38-41].

In this study, we propose a new test rig for studying free fall oblique impacts for a helmeted headform. The test rig, Suspend- $X$, was designed and built at the Head Injury Prevention (HIP) Lab at Simon Fraser University (Surrey, BC, Canada). Suspend-X is a patent-pending test rig [42] that uses a suspending arm instead of a basket frame to hold a detached helmeted headform in place during the fall. For the purpose of this study, Suspend- $X$ was used to perform drop tests at various angles on an American football helmet, to investigate the importance of the duration in addition to the magnitude of an impact.

\section{Available Test Rigs for Oblique Impacts}

\section{Free-fall guided impact machine}

The drop test towers are mostly used to subject a helmeted headform to a guided fall or free-fall via rail with the help of gravity. In the guided fall, the headform is fixed to the carriage using either a surrogate neckform or a solid attachment, which results in limited or no rotational acceleration of the headform.

On the other hand, the free-fall impact test rig allows the headform to freely rebound off the impacted anvil and generate both linear and rotational acceleration after impact. As shown in Figure 1, the helmeted headform is placed on a basket frame that is attached to the rail by a carriage. The basket frame allows the helmeted headform to maintain its position and orientation prior to impacting the anvil.

The basket frame, as shown in Figure 1, has a potential disadvantage when arranged for drop testing onto anvils with steep angles such as $15^{\circ}$ to the vertical, as required in the ECE 22.05 oblique impact testing standard [43]. During such impacts, the helmeted headform may rebound off the anvil and strike the falling basket frame, leading to unintentional damage on the testing apparatus and headform, which in turn could affect the integrity of the system.

\section{Moving headform and impact opponent}

Another method used for evaluating headgear per-

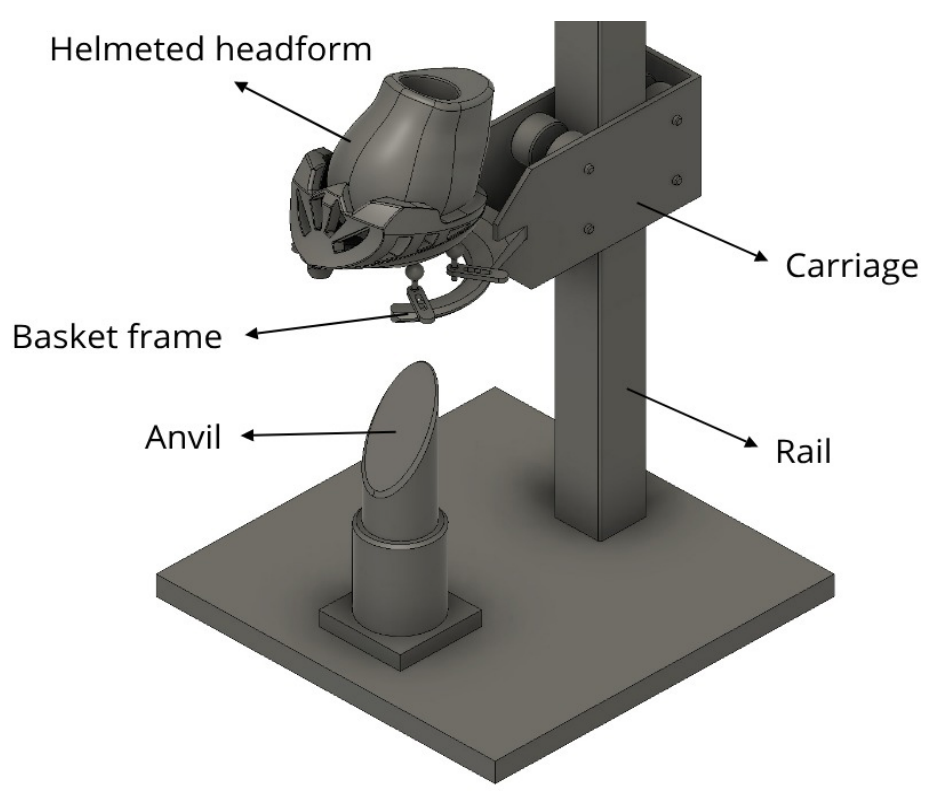

Figure 1: Drop tower with carriage installed with a basket frame to support a helmeted test headform. 
formance with the ATD headform is by generating momentum for both colliding objects, which are the helmeted headform and the anvil [22,34,35]. To create an impact scenario, both helmeted headform and the anvil require to have a certain speed and impact each other at a specific angle to generate the final required speed and angle of impact.

Other studies used a combination of a pendulum and a rail where the headform, fixed to the pendulum arm drops from certain heights to strike an oblique anvil $[25,44]$. The pendulum arm was devised to maintain a levelled headform that would strike perpendicular to the direction of the falling anvil. Testing with a moving plate can present different impact conditions from drop testing onto static anvils. Compared to a vertical drop onto a stationary surface, the horizontal striking plate could produce dissimilar head accelerations due to the different normal forces observed between the two scenarios [45]. By manipulating the speeds of the individual moving objects, the pendulum and plate methods can achieve high resultant impact speeds [25,34]. However, having more moving components adds to the complexity of the testing and causes repeatability and maintenance issues [34,35]. However, such methods can be valuable for reproducing real-life impacts for automotive or sports accidents.

\section{Pendulum and linear impactor}

During standard impact testing for football and ice hockey, a stationary ATD assembly is struck by a moving impactor mass [23,32,46-48]. Pellman, et al. (2006) and Jadischke, et al. (2016) performed testing with a pendulum arm, and a Hybrid III head-neck assembly mounted on a sliding base, which allowed up to five degrees of freedom after an impact. A similar method was used in the hockey impact study by Oeur, et al. (2014), where the impacting mass was rapidly pushed by a pneumatic linear ram towards an ATD assembly.

Testing by linear impactors such as a pneumatic linear ram and a pendulum arm simulates a helmet-to-helmet impact [46], however, it produces little tangential force [45]. Research studies showed that the tangential force is a key contributor to the rotational acceleration of the head $[49,50]$. Furthermore, it is known that injuries can also occur due to impacting against playing surface, body parts, and jersey [51-53], which may not be accurately represented by testing with a linear impactor.

The purpose of using a sliding base in linear impactor tests is to allow movement of a struck object after an impact, as seen in real-life collisions. Pellman, et al. [46] showed that rigidly attaching a head-neck assembly to the base sliding results in excessive loading and does not produce the same impact response as in accident reconstruction. In addition, Walsh, et al. [54] utilized the translating table to simulate torso mass and found no significant difference in linear and rotational responses between rigidly affixing the lower neck of the head-neck assembly versus mounting the lower neck to a $12.78 \mathrm{~kg}$ translating table. A study by Beusenberg, et al. [55] suggested that the effect of changing torso mass was minimal on the head kinematics.

The Hybrid III neckform is commonly used in helmet testing studies despite being too stiff and resulting in high resistance to horizontal and translational motion between the head and body [15,28,29,34]. Hybrid III neckform was originally designed for car crash testing $[15,56]$ and its behaviour is only known for flexion and extension. For other types of motion, such as lateral, the behaviour of the Hybrid III neckform has not been studied [27,30,57].

A study by Nightingale, et al. (1996) suggested a minimum influence of the neck on the head kinematics for the first $9 \mathrm{~ms}$ of impact due to a mechanical separation between the head and neck [58]. Ono, et al. (2003) showed negligible neck muscle activity for the first $50 \mathrm{~ms}$ or $80 \mathrm{~ms}$ of an impact, depending on the impact being anticipated or not [59]. A similar study by Kuramochi, et al. (2004) showed that the muscles of the neck require 13-14 ms to respond to mild impact [60]. Furthermore, there is an atlanto-occipital neutral zone where the neck joint can have motion in the range of $10^{\circ}$ without inducing any force that can affect the kinematics of the head [61,62]. Testing at the HIP Lab, including the ones performed in this study, showed that the rotational displacements of the head during the oblique impacts for the first 10 ms of the impact are less than $10^{\circ}$. In addition, most impact scenarios for helmet testing occur in a period between 7-15 ms, depending on the type of helmet, speed of impact, and contacting surface $[1,63]$. As a result, using a detached headform and a free-fall test rig can more accurately represent the head during an oblique impact compared to the Hybrid III neckform.

\section{Suspension-Based Drop Test}

Following the concept of a free-falling helmeted headform, an alternative approach was taken for oblique impact testing. The main goal of this design is to enable a helmeted headform to freely move during impact and eliminate the need for the basket frame. This is achieved by introducing an arm that the helmeted headform is suspended from. Like the conventional test rigs, Suspend- $X$ comprises a rail, a carriage, and an anvil, as shown in Figure 2a. The main difference between a conventional test rig for oblique impact and Suspend- $X$ is the fact that the basket frame is replaced by a drop assembly that suspends the helmeted headform. The drop assembly is secured to the carriage and consists of a horizontal suspension arm, a vertical bar, and a release mechanism, also shown in Figure 2a. The helmeted headform is suspended on the release mechanism via cords. The cords were 


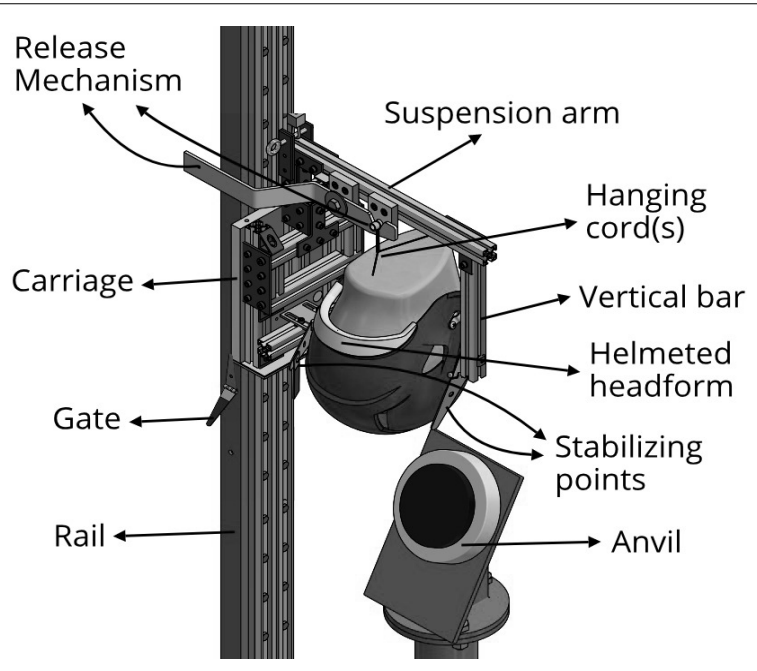

(a)

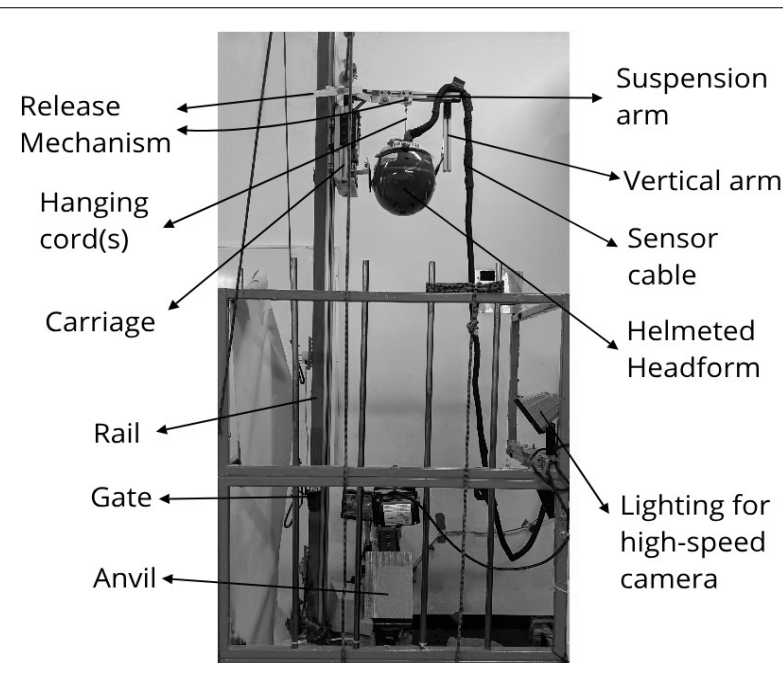

(b)

Figure 2: (a) Suspend-X, a novel oblique impact test rig; (b) Suspend-X built at the HIP lab.

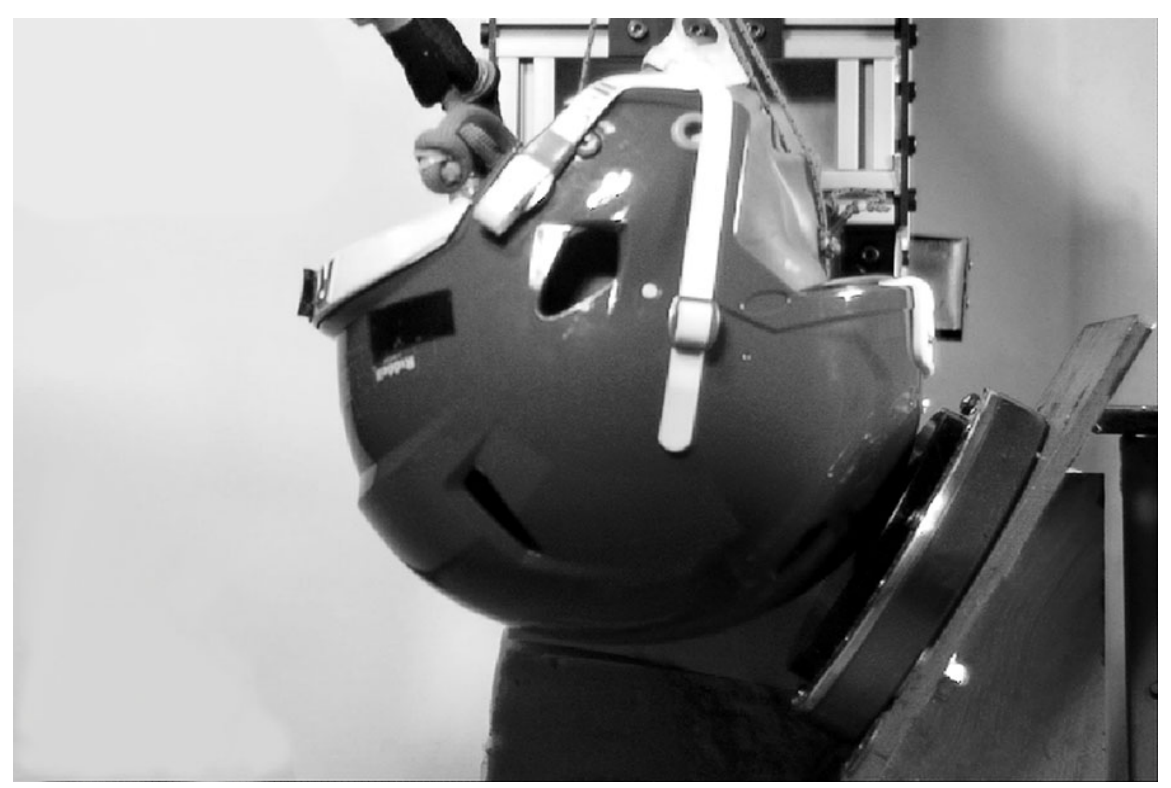

Figure 3: Location of impact on the Riddell Speed helmet.

attached to different locations of the headform to allow the helmeted headform to have a given configuration. Small hook-and-loop fasteners are placed on different locations on the drop assembly as stabilizing points to preserve the suspending configuration. A gate is placed on the rail to trigger the release mechanism and disengage the cords and allow the helmeted headform to start its free-fall motion right before contacting the anvil. The Suspend- $X$ was built at the HIP lab, as shown in Figure $2 b$.

\section{Testing with Suspend-X}

Oblique impacts were performed for different impact scenarios to demonstrate the use of the test rig. The tests also provide insight into the relationship between the angle of impact and the head response. For the purpose of this study, five tests were completed for each angle configuration, and the Coefficient of Variation (CV) was used to monitor the standard deviation of the results compared to the mean value.

Hybrid III headform is widely used in impact testing and is equipped with a removable synthetic skin with a $10 \mathrm{~mm}$ average thickness. Studies have shown that surface conditions between the helmet and the headform can influence the response of the headform during impacts $[64,65]$. Suspend- $X$ can use any other headform such as metal headform, wooden headform, and NOCSAE headform. For the purpose of this study, a Hybrid III $50^{\text {th }}$ percentile adult male headform is used.

The Hybrid III headform was fitted with a Riddell Speed football helmet (size Large). Football helmets were chosen specifically for their resilience in a repeated drop test. All tests were performed without the facemask or any other accessories. For each angle configuration, the helmeted headform was oriented to produce an impact at the frontal region of the helmet, as shown in Figure 3. This orientation corresponds to one of the 
most frequently impacted locations based on the impact studies for football [66-68]. Inside the headform, nine single-axis linear accelerometers (ENDEVCO 7204C) were embedded in a 3-2-2-2 array to determine linear and rotational acceleration based on the methods presented by Padgaonkar, et al. [69]. The rotational velocity was obtained through the integration of the rotational acceleration data. The rotational displacement was calculated by performing double integration of the rotational acceleration data from zero to $10 \mathrm{~ms}$, starting when the pulse rises.

The headform was dropped from a height allowing it to reach a nominal speed of $5.5 \mathrm{~m} / \mathrm{s}$ prior to impacting a 42 Shore A Modular Elastomer Programmer (MEP) pad according to National Operating Committee on Standards for Athletic Equipment (NOCSAE) standard for newly manufactured football helmets [17]. Impact speed was measured using a photoelectric time gate installed adjacent to the guided rail. The anvil was inclined at three angles: $15^{\circ}, 30^{\circ}$, and $45^{\circ}$ to the vertical. A high-speed camera (Edgertronics SC2+) recorded impacts at 4,000 frames per second in high definition to monitor each trial. In each trial, the data collection and video recording sequence were initiated when the drop carriage passed through the first photoelectric sensor. Data from the accelerometers installed in the headform were recorded with a Data Acquisition (DAQ) system (National Instrument) at a $20-\mathrm{kHz}$ sampling rate. LabVIEW software was used to manage the collection and data processing. Measurements from the accelerometers were filtered with a standard fourth-pole Butterworth $1000-\mathrm{Hz}$ low-pass filter following the guidelines set in SAE J211 $[70,71]$.

\section{Results and Discussion}

The results of drop tests with Suspend-X on to an oblique anvil inclined at three distinct angles showed in Table 1. For each impact scenario, the tests were repeated five times. When angled at $15^{\circ}$, the helmeted headform experienced an average peak linear acceleration of $44.74 \mathrm{~g}$, rotational acceleration of $4.69 \mathrm{krad} / \mathrm{s}^{2}$, and rotational velocity of $36.63 \mathrm{rad} / \mathrm{s}$. At $30^{\circ}$, the average peak linear acceleration was $82.10 \mathrm{~g}$, rotational acceleration was $5.36 \mathrm{krad} / \mathrm{s}^{2}$, and rotational velocity was 36.10 $\mathrm{rad} / \mathrm{s}$. At $45^{\circ}$, the helmeted headform experienced an average peak linear acceleration of $96.40 \mathrm{~g}$, rotational acceleration of $4.96 \mathrm{krad} / \mathrm{s}^{2}$, and rotational velocity of $31.38 \mathrm{rad} / \mathrm{s}$.
As shown in Table 1 , by increasing the anvil angle from $15^{\circ}$ to $30^{\circ}$, the linear acceleration increases by $83.5 \%$ and a further increase to $45^{\circ}$ resulted in a $17.4 \%$ increase compared to $30^{\circ}$. An increase in the angle from $15^{\circ}$ to $30^{\circ}$ resulted in an increase in the rotational acceleration by $14.2 \%$. When the angle was increased from $30^{\circ}$ to $45^{\circ}$, the tests resulted in an average of $7.4 \%$ decrease in rotational acceleration. Compared to tests with a $15^{\circ}$ anvil, tests with a $30^{\circ}$ resulted in $1.5 \%$ lower rotational velocity. The rotational velocity decreased further by $14.3 \%$ when dropping onto a more gradual sloped surface at $45^{\circ}$ compared to $30^{\circ}$. The results showed that increasing the angle of impact from $15^{\circ}$ to $45^{\circ}$ increased the linear acceleration and decreased rotational velocity. However, rotational acceleration does not follow the same pattern as it increased as the angle of impact was increased from $15^{\circ}$ to $30^{\circ}$ and decreased from $30^{\circ}$ to $45^{\circ}$. Sample graphs of each type of impact for linear acceleration, rotational acceleration, and rotational velocity are shown in Figure 4a, Figure 4b, Figure $4 c$, respectively. With an increase in the anvil angle from $15^{\circ}$ to $30^{\circ}$, the linear and rotational acceleration responses mainly became higher in magnitude and shorter in duration while the rotational velocity decreased. Furthermore, increasing the anvil angle from $30^{\circ}$ to $45^{\circ}$ resulted in another increase in peak linear acceleration and a decrease in peak rotational acceleration and rotational velocity.

Research studies have shown that kinematic parameters of the head, such as linear acceleration, rotational acceleration, and rotational velocity, are closely linked to the risk and severity of the head injury [5,72-80]. The human brain can tolerate a relatively high magnitude of acceleration in a short period of time. However, when the period of acceleration becomes longer, the same impact magnitude can cause extensive damage to the brain $[63,75]$. Therefore, to determine the severity of an impact, having information about the magnitude and duration of the acceleration is paramount, and a helmet evaluation criterion requires to consider both factors in rating a helmet performance.

\section{Conclusion}

A new suspension-based oblique impact test rig for testing helmets was introduced. The test rig is a freefall system where a helmeted headform is suspended instead of being placed on a basket frame and detaches from the system before the impact allowing an un-

Table 1: The average response of a detached Hybrid III struck at the FY region with varying angles (List of abbreviations: Accel.: Acceleration; Ave.: Average; CV: Coefficient of Variation; Lin.: Linear; No.: Number; Rot.: Rotational; Vel.: Velocity; Disp.: Displacement).

\begin{tabular}{|c|c|c|c|c|c|c|c|c|}
\hline $\begin{array}{l}\text { Impact } \\
\left.\text { Angle ( }{ }^{\circ}\right)\end{array}$ & $\begin{array}{l}\text { Ave. Lin. } \\
\text { Accel. (g) }\end{array}$ & $\begin{array}{l}\text { Lin. Accel. } \\
\text { CV (\%) }\end{array}$ & $\begin{array}{l}\text { Ave. Rot. Accel. } \\
\left(\mathrm{krad} / \mathrm{s}^{2}\right)\end{array}$ & $\begin{array}{l}\text { Rot. Accel. } \\
\text { CV (\%) }\end{array}$ & $\begin{array}{l}\text { Ave. Rot. } \\
\text { Vel. (rad/s) }\end{array}$ & $\begin{array}{l}\text { Rot. Vel. } \\
\text { CV (\%) }\end{array}$ & $\begin{array}{l}\text { Ave. Rot. } \\
\text { Disp. ( () }\end{array}$ & $\begin{array}{l}\text { Rot. Disp. CV } \\
(\%)\end{array}$ \\
\hline 15 & 44.74 & 2.78 & 4.69 & 4.39 & 36.63 & 1.00 & 6.14 & 7.39 \\
\hline 30 & 82.10 & 1.90 & 5.36 & 1.36 & 36.10 & 1.39 & 6.72 & 3.73 \\
\hline 45 & 96.40 & 5.44 & 4.96 & 3.05 & 31.38 & 5.20 & 6.25 & 7.07 \\
\hline
\end{tabular}




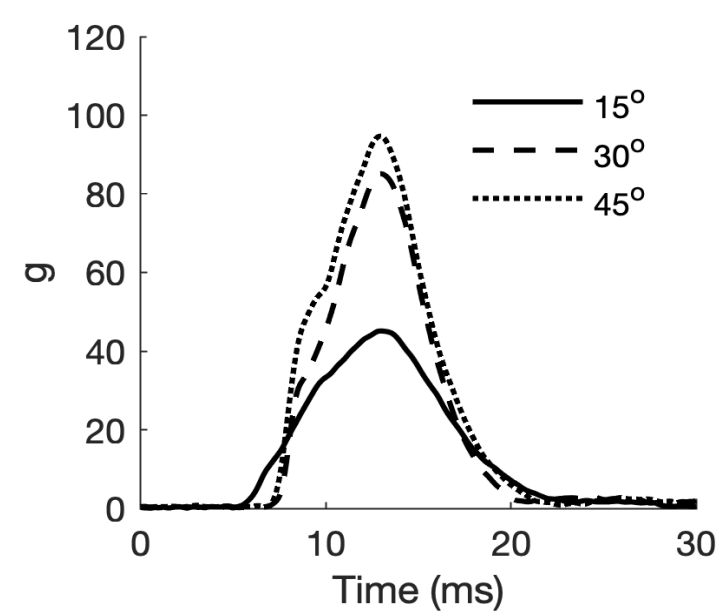

(a)

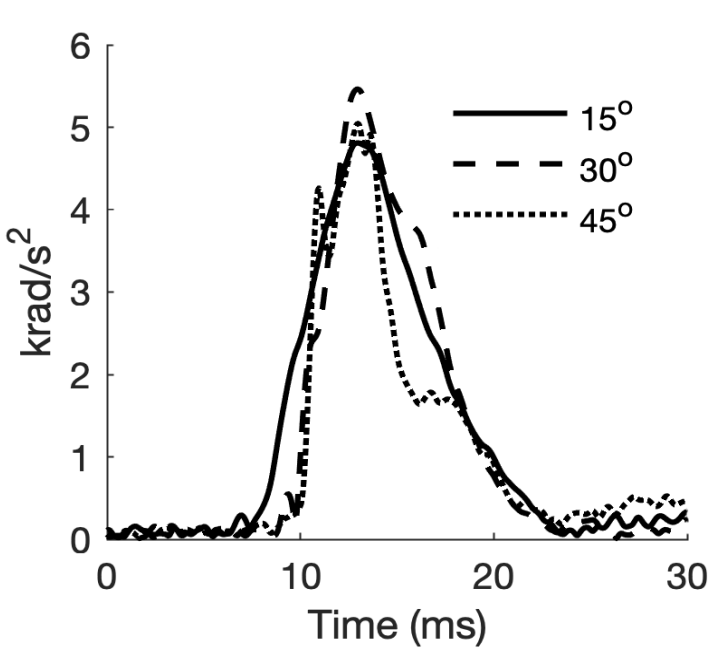

(b)

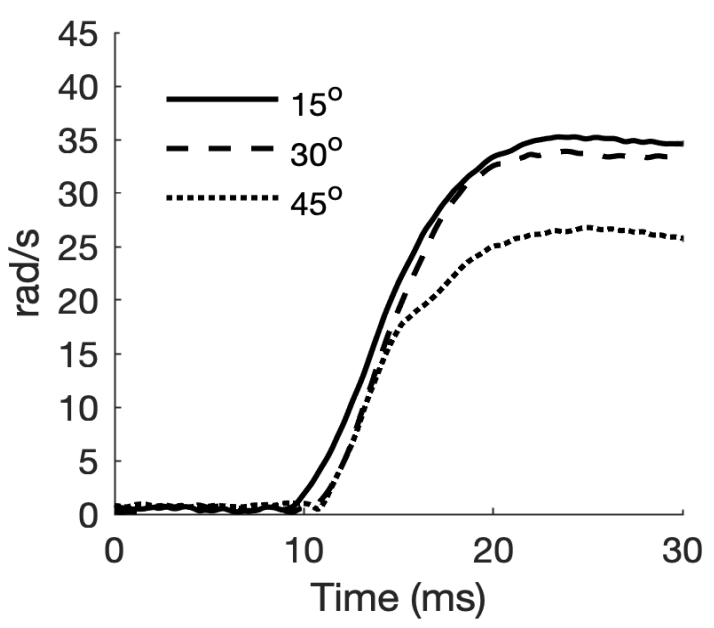

(c)

Figure 4: Plotting impact duration versus (a) linear acceleration; (b) rotational acceleration, (c) rotational velocity.

restricted motion. Suspend-X showed to be effective in performing helmet impact tests at different angles. In addition, the test results showed low CVs and high repeatability within the same impact scenario. The results showed that the proposed test rig can perform oblique impact tests on a wide range of angles without causing damage to the test rig. The results of the impact tests performed with Suspend- $X$ showed that studying both the magnitude and duration of an impact test is necessary to evaluate a helmet performance.

\section{Acknowledgments}

This work was supported in part by grants from MITACS (10-11-4005-JJ) and the Natural Sciences and Engineering Council of Canada (PJ/421433/2011).

\section{References}

1. Pellman EJ, Viano DC, Tucker AM, Casson IR, Waeckerle JF (2003) Concussion in professional football: reconstruction of game impacts and injuries - part 1 . Neurosurgery 53 : 799-814.

2. Langlois JA, Rutland-Brown W, Wald MM (2006) The epidemiology and impact of traumatic brain injury. J Head Trauma Rehabil 21: 375-378.

3. Hansen K, Dau N, Feist F, Deck C, Willinger R (2013) Angular Impact Mitigation system for bicycle helmets to reduce head acceleration and risk of traumatic brain injury. Accid Anal Prev 59: 109-117.

4. Bachynski KE, Goldberg DS (2014) Youth sports and public health: framing risks of mild traumatic brain injury in american football and ice hockey. J Law Med Ethics 42: 323-333.

5. Holbourn A, Edin M, Oxfd Phil D (1943) Mechanics of head injuries. The Lancet 242: 438-441.

6. Gurdjian ES, Lissner HR, Hodgson VR, Patrick LM (1964) Mechanism of head injury. Clin Neurosurg 12: 112-128.

7. McElhaney JH, Roberts VL, Hilyard JF, Kenkyūjo NJ (1976) Properties of human tissues and components: nervous tissues. Handbook of human tolerance, Tokyo, Japan Automobile Research Institute Inc 143.

8. Andriessen TM, Jacobs B, Vos PE (2010) Clinical characteristics and pathophysiological mechanisms of focal and diffuse traumatic brain injury. J Cell Mol Med 14: 2381-2392.

9. Gennarelli TA (1993) Mechanisms of brain injury. J Emerg Med 11 Suppl 1: 5-11.

10. Meaney D, Smith D, Shreiber D, Bain A, Miller R, et al. (1995) Biomechanical Analysis of Experimental Diffuse Axonal Injury. Journal of Neurotrauma 12: 689-694.

11. Ommaya AK, Goldsmith W, Thibault L (2002) Biomechanics and neuropathology of adult and paediatric head injury. Br J Neurosurg 16: 220-242.

12. Kleiven $S$ (2013) Why most traumatic brain injuries are not caused by linear acceleration but skull fractures are. Front Bioeng Biotechnol 1: 1-5.

13. Kerr ZY, Marshall SW, Guskiewicz KM (2011) Reliability of concussion history in former professional football players. Medicine and Science in Sports and Exercise 44: 377-382.

14. Robbins CA, Daneshvar DH, Picano JD, Gavett BE, Baugh CM, et al. (2014) Self-reported concussion history: impact of providing a definition of concussion. Open Access $\mathrm{J}$ Sports Med 5: 99-103.

15. Whyte T, Stuart C, Mallory A, Ghajari M, Plant DJ, et al. (2019) Cripton A review of impact testing methods for headgear in sports: considerations for improved prevention of head injury through research and standards. J Biomech Eng 141: 070803. 
16. (1998) CPSC, Safety Standard for Bicycle Helmets, Washington, DC: Consumer Product Safety Commission, Standard No. 16 CFR Part 1203.

17. (2017) National Operating Committee on Standards for Athletic Equipment, ND002-17m19: Standard Performance Specification for Newly Manufactured Football Helmets, Overland Park, KS: NOCSAE.

18. (2016) National Operating Committee on Standards for Athletic Equipment, ND030-11m16: Standard Performance Specification for Newly Manufactured Ice Hockey Helmets, Overland Park, KS: NOCSAE.

19. Johnston J, Ning H, Kim J, Kim Y, Soni B, et al. (2015) Simulation, fabrication, and impact testing of a novel football helmet padding system that decreases rotational acceleration. Sports Eng 18: 11-20.

20. McIntosh AS, Patton DA (2012) Impact reconstruction from damage to pedal and motorcycle helmets. Journal of Sports Engineering and Technology 226: 274-281.

21. Bland ML, Zuby DS, Mueller BC, Rowson S (2018) Differences in the protective capabilities of bicycle helmets in real-world and standard-specified impact scenarios. Traffic Inj Prev 19: 158-163.

22. Pang TY, Thai KT, McIntosh AS, Grzebieta R, Schilter E, et al. (2011) Head and neck responses in oblique motorcycle helmet impacts: a novel laboratory test method. International Journal of Crashworthiness 16: 297-307.

23. Jadischke R, Viano DC, McCarthy J, King Al (2016) The effects of helmet weight on Hybrid III head and neck responses by comparing unhelmeted and helmeted impacts. Journal of Biomechanical Engineering 138.

24. Bliven E, Rouhier A, Tsai S, Willinger R, Bourdet N, et al. (2019) Evaluation of a novel bicycle helmet concept in oblique impact testing. Accid Anal Prev 124: 58-65.

25. Siegkas P, Sharp DJ, Ghajari M (2019) The traumatic brain injury mitigation effects of a new viscoelastic add-on liner. Scientific Reports.

26. Walsh ES, Kendall M, Post A, Meehan A, Hoshizaki TB (2018) Comparative analysis of Hybrid III neckform and an unbiased neckform. Sports Engineering 21: 479-485.

27. Bartsch A, Benzel E, Miele V, Morr D, Prakash V (2012) Hybrid III anthropomorphic test device (ATD) response to head impacts and potential implications for athletic headgear testing. Accid Anal Prev 48: 285-291.

28. Myers BS, McElhaney JH, Doherty BJ, Paver JG, Nightingale RW, et al. (1989) Response of the Human Cervical Spine to Torsion. 33rd Stapp Car Crash Conference, Washington, DC.

29. Svensson MY, Lovsund P (1992) A Dummy for Rear-End Collisions - Development and Validation of a New Dummy-Neck. IRCOBI Conference, Verona, Italy.

30. Gwin GT, Chu JJ, Solomon G, Diamond P, Halstead D, et al. (2009) An Investigation of the NOCSAE Linear Impactor Test Method Based on In Vivo Measures of Head Impact Acceleration in American Football. Journal of Biomechanical Engineering 132: 1.

31. Nelson TS, Cripton PA (2010) A new biofidelic sagittal plane surrogate neck for head-first impacts. Traffic Inj Prev 11: $309-319$

32. Clark JM, Post A, Hoshizaki TB, Gilchrist MD (2016) Protective capacity of ice hockey helmets against different impact events. Ann Biomed Eng 44: 3693-3704.
33. Halldin P, Gilchrist A, Mills NJ (2001) A new oblique impact test for motorcycle helmets. International Journal of Crashworthiness 6: 53-64.

34. Aare M, Halldin P (2003) A new laboratory rig for evaluating helmets subject to oblique impacts. Traffic Injury Prevention 4: $240-248$

35. Mclntosh AS, Lai A, Schilter E (2013) Bicycle helmets: head impact dynamics in helmeted and unhelmeted oblique impact tests. Traffic Inj Prev 14: 501-508.

36. Chinn B, Canaple B, Derler S, Doyle D, Otte D, et al. (2001) COST 327 Motorcycle Safety Helmets. European Commission Directorate General for Energy and Transport, Belgium.

37. Hering A, Derler S (2000) Motorcycle helmet drop tests using a Hybrid III dummy. Montpellier, France.

38. Bland ML, McNally C, Rowson S (2018) STAR Methodology for Bicycle Helmets. Virginia Polytechnic Institute and State University, Blacksburg, Virgina.

39. Bland ML, McNally C, Rowson S (2018) Headform and neck effects on dynamics response in bicycle helmet oblique impact testing. IRCOBI Conference Proceedings, Athens, Greece.

40. Stigson H, Rizzi M, Ydenius A, Engstrom E, Kullgren A (2017) Consumer testing of bicycle helmets. IRCOBI Conference Proceedings, Antwerp, Belgium.

41. Klug C, Feist F, Tomasch E (2015) Testing of bicycle helmets for preadolescents. ICROBI Conference Proceedings, Lyon, France.

42. Abram DE, Golnaraghi F, Wang G (2018) Suspension-based Impact System. Patent No. 62/636732.

43. United Nations Economic Commission for Europe (2002) Regulation 22.05 - Uniform provisions concerning the approval of protective helmets and their visors for drivers and passengers of motor cycles and mopeds, Geneva.

44. Roseveare AJ, Plant DJ, Ghajari M (2016) A new helmet-liner design for improved survivability. ICROBI Conference Proceedings, Malaga, Spain.

45. Willinger $R$, Halldin $P$, Bogerd $C P$, Deck $C$, Fahlstedt $M$ (2015) Final report of Working Group 3: Impact Engineering. COST Action TU1101/HOPE collaboration, Brussels, Belgium.

46. Pellman EJ, Viano DC, Withnall C, Shewchenko N, Bir CA, et al. (2006) Concussion in professional football: helmet testing to assess impact performance - part 11. Neurosurgery 58: 78-96.

47. Post A, Oeur A, Hoshizaki B, Gilchrist MD (2013) Examination of the relationship between peak linear and angular accelerations to brain deformation metrics in hockey helmet impacts. Computer Methods in Biomechanics and Biomedical Engineering 16: 511-519.

48. Oeur RA, Zanetti K, Hoshizaki TB (2014) Angular Acceleration Responses of American Football, Lacrosse and Ice Hockey Helmets Subject to Low-Energy Impacts. IRCOBI Conference.

49. Finan JD, Nightingale RW, Myers BS (2008) The Influence of Reduced Friction on Head Injury Metrics in Helmeted Head Impacts. Traffic Injury Prevention 9: 483-488.

50. Abram DE, Wikarna A, Golnaraghi F, Wang GG (2019) A Modular Impact Diverting Mechanism for Football Helmets. Journal of Biomechanics.

51. Naunheim R, McGurren M, Standeven J, Fucetola R, Lau- 
ryssen C, et al. (2002) Does the use of artificial turf contribute to head injuries? J Trauma 53: 691-694.

52. Withnall C, Shewchenko N, Gitttens R, Dvorak J (2005) Biomechanical investigation of head impacts in football. $\mathrm{Br} \mathrm{J}$ Sports Med 39: 49-57.

53. Rossi AM, Claiborne TL, Thompson GB, Todaro S (2016) The Influence of Friction Between Football Helmet and Jersey Materials on Force: A Consideration for Sport Safety. J Athl Train 51: 701-708.

54. Walsh ES, Kendall M, Hoshizaki TB, Gilchrist MD (2014) Dynamic impact response and predicted brain tissue deformation comparison for an impacted hybrid III headform with and without a neckform and torso masses. IRCOBI Conference.

55. Beusenberg M, Shewchenko N, Newman JA, de Lange R, Cappon H (2001) Head, Neck, and Body Coupling in Reconstructions of Helmeted Head Impacts. IRCOBI Conference.

56. Foster JK, Kortge JO, Wolanin MJ (1997) Hybrid III-A Biomechanically-Based Crash Test Dummy. SAE Technical Paper 770938.

57. Herbst B, Forrest S, Chang D (1998) Fidelity of Anthropometric Test Dummy Necks in Rollover Accidents. 16th International Technical Conference on the Enhanced Safety of Vehicles, Windsor, ON, Canada.

58. Nightingale RW, McElhaney JH, Richardson WJ, Myers BS (1996) Dynamic Responses of the Head and Cervical Spine to Axial Impact Loading. J Biomechanics 29: 307-318.

59. Ono K, Kaneoka K, Fukushima M, Uwai H, Ujihashi S (2003) Biomechanical response of the head, neck, and torso to direct impact on the back of male and female volunteers. IRCOBI Conference, Lisbon.

60. Kuramochi R, Kimura T, Nakazawa K, Akai M, Torii S, et al. (2004) Anticipatory modulation of neck muscle reflex responses induced by mechanical perturbations of the human forehead. Neurosci Lett 366: 206-210.

61. Camacho DL, Nightingale RW, Robinette JJ, Vanguri SK, Coates DJ et al. (1997) Experimental Flexibility Measurements for the Development of a computational Head-Neck Model Validated for Near-Vertex Head Impact. SAE 973345

62. Ivancic PC (2014) Cervical spine instability following axial compression injury: A biomechanical study. Orthop Traumatol Surg Res 100: 127-133.

63. Hoshizaki T, Post A, Kendall M, Cournoyer J, Rousseau P, et al. (2017) The development of a threshold curve for the understanding of concussion in sport. Trauma 19: 196-206.

64. Ebrahimi I, Golnaraghi F, Wang GG (2015) Factors Influencing the oblique impact test of motorcycle helmets. Traffic Inj Prev 16: 404-408.

65. Trotta A, Ní Annaidh A, Burek RO, Pelgrims B, Ivens J
(2018) Evaluation of the head-helmet sliding properties in an impact test. J Biomech 75: 28-34.

66. Pellman EJ, Viano DC, Tucker AM, Casson IR; Committee on Mild Traumatic Brain Injury, National Football League (2003) Concussion in professional football: location and direction of helmet impacts - Part 2. Neurosurgery 53: 13281341.

67. Crisco JJ, Fiore R, Beckwith JG, Chu JJ, Brolinson PG, et al. (2010) Frequency and location of head impact exposures in individual collegiate football players. J Athl Train 45: 549-559.

68. Daniel R, Rowson S, Duma S (2012) Head impact exposure in youth football. Ann Biomed Eng 40: 976-981.

69. Padgaonkar A, Krieger K, King A (1975) Measurement of Angular Acceleration of a Rigid Body Using Linear Accelerometers. Journal of Applied Mechanics 42: 552-556.

70. (1995) Society for Automotive Engineers. J211-1: Instrumentation for Impact Test - Part 1 - Electronic Instrumentation, Warrendale, PA: SAE International.

71. (2017) National Operating Committee on Standards for Athletic Equipment, ND001-17m17b: Standard Test Method and Equipment Used in Evaluating The perforrmance Characteristics of Headgear/Equipment. Overland Park, KS: NOCSAE.

72. Hodgson V, Thomas L (1971) Comparison of Head Acceleration Injury Indices in Cadaver Skull Fracture. SAE Technical Paper 710854.

73. Rowson S, Duma SM (2013) Brain injury prediction: assessing the combined probability of concussion using linear and rotational head acceleration. Ann Biomed Eng 41: 873-882.

74. Gennarelli T, Thibault L, Ommaya A (1972) Pathophysiologic Responses to Rotational and Translational Accelerations of the Head. SAE Technical Paper 720970.

75. Gurdjian ES, Roberts VL, Thomas LM (1966) Tolerance curves of acceleration and intracranial pressure and protective index in experimental head injury. J Trauma 6: 600-604.

76. Ommaya AK, Hirsch AE, Yarnell P, Harris EH (1967) Scaling of Experimental Data on Cerebral Concussion in Sub-human Primates to Concussion Threshold for Man. Stapp Car Crash Conference, Anaheim, California.

77. Versace J (1971) A review of the severity index. SAE Technical Paper 710881.

78. Willinger R, Baumgartner D (2003) Human head tolerance limits to specific injury mechanism. IJCrash 8: 605-617.

79. Post A, Hoshizaki TB (2012) Mechanism of brain impact injuries and their prediction: a review. Trauma 0: 1-23.

80. Broglio SP, Schnebel B, Sosnoff JJ, Shin S, Feng X, et al. (2010) The Biomechanical Properties of Concussions in High School Football. Med Sci Sports Exerc 42: 2064-2071. 